\title{
Culturable airborne fungi in outdoor environments in Beijing, China
}

\author{
Zhiguo Fang ${ }^{\mathrm{a}}$, Zhiyun Ouyang ${ }^{\mathrm{a}, *}$, Lifeng Hu${ }^{\mathrm{b}}$, Xiaoke Wang ${ }^{\mathrm{a}}$, \\ Hua Zheng ${ }^{\mathrm{a}}$, Xueqiang Lin ${ }^{\mathrm{a}}$ \\ ${ }^{a}$ Key Lab of Systems Ecology, Research Center for Eco-Environmental Sciences, \\ Chinese Academy of Sciences, P.O. Box 2871, Beijing, 100085, ROC \\ ${ }^{\mathrm{b}}$ College of Bio-Safety Science and Technology, Hunan Agriculture University, Changsha 410128, ROC
}

Received 20 October 2004; accepted 31 January 2005

Available online 17 March 2005

\begin{abstract}
Airborne fungi are being proposed as a cause of adverse health effects. They may adversely affect human health through allergy, infection, and toxicity. Moreover, they have a great influence on urban air quality in Beijing. In this study, a systematical survey on the culturable airborne fungi was carried out for 1 year in Beijing urban area. Fungal samples were collected for $3 \mathrm{~min}$, three times each day, and continued for three consecutive days of each month with FA-1 sampler from three sampling sites. Results showed that the culturable fungal concentrations ranged from 24 CFU (Colony forming units) $/ \mathrm{m}^{3}$ to $13960 \mathrm{CFU} / \mathrm{m}^{3}$, and the mean and median was $1165 \mathrm{CFU} / \mathrm{m}^{3}$ and $710 \mathrm{CFU} / \mathrm{m}^{3}$, respectively. Fungal concentrations in the greener area around the Research Center for Eco-Environmental Sciences (RCEES) and Beijing Botanical Garden (BBG) were significantly higher than in the densely urban and highly trafficked area of Xizhimen (XZM) $(* * * P<0.001)$, but no significant difference was found between RCEES and BBG $(P>0.05)$. The variation of fungal concentrations in different seasons was significant in RCEES and BBG, where the concentrations were higher in Summer and Autumn, and lower in Spring and Winter. However, there were no significant differences in fungal concentrations between the Spring and the Winter for three sampling sites $(P>0.05)$. Fourteen genera, including 40 species of culturable fungi, were identified in this study. Penicillium, with the most abundant species, which comprised more than $50 \%$ of the total isolated fungal species. Cladosporium were the most dominant fungal group, and contributed to more than one third of the total fungal concentration, followed by non-sporing isolates, Alternaria, Pencillium and Asperigillus. The concentration percentage of Cladosporium was significantly higher in RCEES than in XZM $(* P<0.05)$, and the concentration percentages of Penicillium $(* * P<0.01)$ and Aspergillus $(* P<0.05)$ were higher in XZM than in RCEES and in BBG. For other groups' concentration percentages, no significant differences were observed among the sampling sites.
\end{abstract}

\footnotetext{
* Corresponding author. Tel.: +8610 62849191; fax: +86 1062943822.

E-mail address: zyouyang@mail.rcees.ac.cn (Z. Ouyang).
} 
The distribution pattern of airborne fungi presented log-normal distribution. The highest proportion of culturable fungi was detected in stage $4(2.0-3.5 \mu \mathrm{m})$, and the lowest was in stage $6(<1.0 \mu \mathrm{m})$.

(c) 2005 Elsevier B.V. All rights reserved.

Keywords: Culturable airborne fungi; Bioaerosol; Aerobiology; Size distribution pattern

\section{Introduction}

Airborne fungi are among the most common organisms in nature. They were considered to be correlated with air pollution and were proposed as a cause of adverse health effects on humans, animals and plants (Harrison et al., 1992; Bush and Portnoy, 2001; Ren et al., 2001; Shelton et al., 2002). Elevated levels of particle air pollution were associated with a decreased lung function, increased respiratory symptoms such as coughing, shortness of breath, wheezing and asthma attacks, as well as chronic obstructive pulmonary disease, cardiovascular disease and lung cancer (Hargreaves et al., 2003; Li and Hsu, 1997; Halonen et al., 1997). More than 80 genera of fungi were reported to be associated with symptoms of respiratory tract allergies (Horner et al., 1995), and over 100 species of fungi were involved with serious human and animal infections, while many other species caused serious plant diseases (Cvetnić and Pepeljnjak, 1997). Cladosporium, Alternaria, Aspergillus and Fusarium were amongst the most common allergenic genera. For example, elevated concentrations of Cladosporium were usually associated with respiratory symptoms (Su et al., 1992). Similarly, higher concentrations of Cladosporium and Penicillium indoor could cause allergic diseases ( $\mathrm{Li}$ et al., 1995). Further more, Reponen et al. (1996) showed that the deposition of fungal spores in lungs and their effects on human health not only depended on their composition (genera and species) and concentration, but also their size. Larger spores $(>10 \mu \mathrm{m})$ were deposited in the upper airway (nose, pharynx) and might result in hay fever symptoms, while smaller spore particles (diameter $<10 \mu \mathrm{m}$, especially $<5 \mu \mathrm{m}$ ) could penetrate the lower airways and might lead to other allergies or asthma (Horner et al., 1995). Attached or unattached fungal allergens that were in the ultra fine range $(<0.1 \mu \mathrm{m})$ or submicrometre size, respectively, could penetrate to the deepest parts of the respiratory tract (Horner et al., 1995).
For their adverse effects on the human health, many studies were carried out about the fungal community both in outdoor and indoor environments. It was reported that the dominant fungi were Cladosporium, Alternaria, Penicillium, Aspergillus in the atmosphere (Pandit et al., 1995; Singh et al., 1995; Rosas et al., 1997; Waisel et al., 1997; Picco and Rodolfi, 2000; Huang et al., 2002; Shelton et al., 2002; Hargreaves et al., 2003; Kuder, 2003; Adhikari et al., 2004), and their concentrations differed from place to place because of local environmental variables, fungal substrates, and human activities (Banerjee et al., 1987; Li and Kendrick, 1994; Hameed and Khodr, 2001; Shelton et al., 2002). However, little is known about the species, number, and size distribution of airborne fungi in Beijing. Therefore, it is indispensable to survey on both concentration distribution and species of airborne fungi systematically and extensively across different environments in Beijing. Three sampling sites in different functional areas were selected for the research on community structure and dynamic change of culturable fungi in Beijing city. The objectives of this study were (i) to describe the groups, concentrations, size distributions, and relative frequencies of airborne culturable fungi in outdoor environments, and (ii) to reveal the distribution characteristics and dynamic changes of fungal concentrations in three sampling sites in Beijing.

\section{Materials and methods}

\subsection{Sampling sites}

Beijing has a territorially monsoon climate and is situated in a warm temperate zone, which has a dry season from November to April and a wet season from May to October. Beijing is the political and cultural center of China, and is also one of the 10 
most populous cities in the world, with about 13 million inhabitants. Three sites were selected for the study in Beijing: (i) Research Center for EcoEnvironmental Sciences (RCEES), a culture and education region, situated in the Haidian district in the northwest part of the city, about $17 \mathrm{~km}$ from the city center, with a green area contributing to about $50 \%$ of the total area, and a few flows of vehicle and personnel. (ii) Xizhimen (XZM), a main traffic junction, located in the Xicheng district near the city center, with a little green area amounting to no more than $5 \%$ vegetation coverage and about 150 time $\mathrm{min}^{-1}$ flow of vehicles, and a few flows of personnel. (iii) Beijing Botanical Garden (BBG), a garden green region, located in the Haidian district over $30 \mathrm{~km}$ from the city center, with a green area contributing to more than $95 \%$ of the total area and few flows of vehicle and personnel.

\subsection{Sampling methods}

A six-stage culturable FA-1 sampler (imitated Andersen sampler), made by the Applied Technical Institute of Liaoyang, China, was used to isolate culturable fungi from the atmosphere. Each stage includes a plate with 400 holes of uniform diameter through which air is drawn at $28.31 \mathrm{~min}^{-1}$ to impact on petri dishes containing agar media. Airborne particles are separated into six fractions, and the aerodynamic cut-size diameters in six stages are 7.0 $\mu \mathrm{m}$ (stage 1), 4.7-7.0 $\mu \mathrm{m}$ (stage 2), 3.3-4.7 $\mu \mathrm{m}$ (stage 3), 2.1-3.3 $\mu \mathrm{m}$ (stage 4), 1.1-2.1 $\mu \mathrm{m}$ (stage 5), and $0.65-1.1 \mu \mathrm{m}$ (stage 6), respectively. In each sampling site, the sampler was mounted on $1.5 \mathrm{~m}$ above ground level with a platform. Sampling was conducted from June 2003 to May 2004. Samplers were collected for 3 min, three times (9:00, 13:00 and 17:00 hours) each day, and continued for three consecutive day of each month. For each sampling, the FA-1 sampler was loaded with $9.0 \mathrm{~cm}$ petri dishes containing Sabouraud agar adding chloramphenicol to inhibit bacterial growth. Exposed culture dishes were incubated for $72 \mathrm{~h}$ at $25{ }^{\circ} \mathrm{C}$. Results were then expressed as colony forming units per cubic meter of air $\left(\mathrm{CFU} / \mathrm{m}^{3}\right)$. CFU/ $\mathrm{m}^{3}$ was calculated as:

(Number of colonies $\times 1000)$ $/($ Sampling time $\times$ Velocity of air flow $)$

\subsection{Fungal identification}

After incubation, fungal colonies growing on each dish were counted and identified to their genus groups according to their microscopic morphology of hyphae, conidia and sporangia. Fungi subcultured onto malt extract agar (MEA), or other appropriate media that have not developed sporing structures after 14 days were described as "non-sporing isolates". The fungi selected from sampling sites were identified to their species using the Biolog Microstation System (Biolog, Hayward, CA).

Biolog MicroPlates were used to test the ability of a microorganism assimilating or oxidizing compounds from a preselected panel of different carbon sources. The test yielded a characteristic pattern of reddish-orange wells and turbidity changes, which constituted a "metabolic fingerprint". All necessary nutrients and biochemicals were prefilled and dried into the 96 wells of the plate. Iodonitrotetrazolium violet was used as a redox dye to colorimetrically indicate the mitochondrial activity that was stimulated during the oxidation of certain carbon sources. The MicroPlates were incubated for 1-4 days. The pattern of reddish-orange and turbid wells was read with the Biolog MicroStation ${ }^{\text {TM }}$ Reader at both 490 $\mathrm{nm}$ and $750 \mathrm{~nm}$ to detect and quantify both color and turbidity responses. Biolog's MicroLog computer software automatically cross-referenced the pattern to an extensive library of species. If an adequate match was found, a presumptive identification of the isolate was made.

\subsection{Statistical analysis}

All the experimental data were analyzed using SPSS Version 10.0 (SPSS, Standard Version) for oneway analysis of variance (ANOVA).

\section{Results}

\subsection{Fungal concentrations}

\subsubsection{Overall concentration}

Considering all sampling sites, the concentration range of culturable fungi was 24-13960 $\mathrm{CFU} / \mathrm{m}^{3}$, and the mean and median were $1165 \mathrm{CFU} / \mathrm{m}^{3}$ and 
Table 1

Concentration data on total airborne fungi in three sampling sites $\left(\mathrm{CFU} / \mathrm{m}^{3}\right)$

\begin{tabular}{lrllc}
\hline Sampling site & Mean & Median & $\begin{array}{l}\text { Minimal } \\
\text { level }\end{array}$ & $\begin{array}{l}\text { Maximal } \\
\text { level }\end{array}$ \\
\hline RCEES & 1357 & 773 & 71 & 8938 \\
XZM & 791 & 586 & 24 & 5329 \\
BBG & 1332 & 838 & 94 & 13960 \\
General & 1165 & 710 & 24 & 13960 \\
\hline
\end{tabular}

$710 \mathrm{CFU} / \mathrm{m}^{3}$, respectively (see Table 1 ). Significantly higher fungal concentrations were found in RCEES and in BBG than in XZM $(* * * P<0.001)$. The mean concentration was $1357 \mathrm{CFU} / \mathrm{m}^{3}$ (71$\left.8938 \mathrm{CFU} / \mathrm{m}^{3}\right)$ in RCEES, for $791 \mathrm{CFU} / \mathrm{m}^{3}(24$ $\left.5329 \mathrm{CFU} / \mathrm{m}^{3}\right)$ in $\mathrm{XZM}$, and for $1332 \mathrm{CFU} / \mathrm{m}^{3}(94$ $13960 \mathrm{CFU} / \mathrm{m}^{3}$ ) in BBG (see Table 1). The concentrations of Cladosporium and Alternaria in RCEES and in BBG were higher than those in XZM $(* * P<0.01)$, but no significant difference was found between RCEES and BBG $(P>0.05)$. Concerning non-sporing isolates, a highest concentration was observed in BBG $(* * * P<0.001)$. However, there were no significant differences of Penicillius and Aspergillus concentrations in all sampling sites $(P>0.05)$ (see Fig. 1).

\subsubsection{Seasonal concentration}

Significant differences in fungal concentrations among seasons existed in RCEES and in BBG, where the mean concentrations were higher in Summer (months from June to August) and Autumn (months from September to November), and lower in Spring

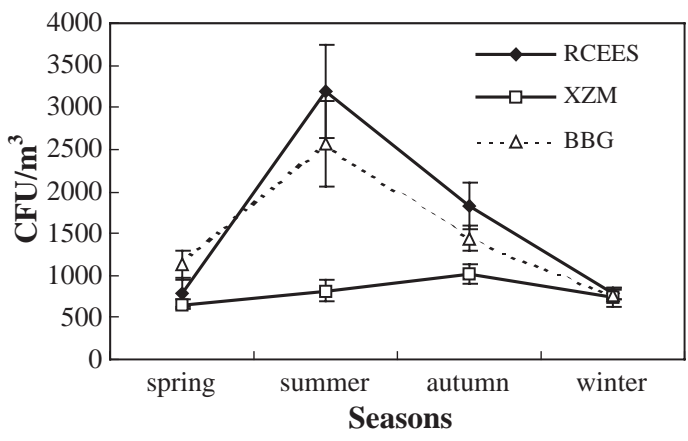

Fig. 2. Seasonal variation patterns of the airborne concentration of total culturable fungi.

(months from March to May) and Winter (months from December to February) $(* * P<0.01)$, while no significant variation of fungal concentrations was observed in different seasons in XZM $(P>0.05)$. In three sampling sites, there were no significant differences in fungal concentrations between Spring and Winter $(P>0.05)$. In RCEES and BBG, the concentration was highest during Summer $(* * P<0.01)$, accounting for $3975.3 \mathrm{CFU} / \mathrm{m}^{3}$ and $2566.5 \mathrm{CFU} / \mathrm{m}^{3}$, respectively. (see Fig. 2).

\subsubsection{Monthly concentration}

The total fungal concentrations from June to October were higher than those of other months in a year in RCEES and in BBG $\left({ }^{*} P<0.05\right)$. The highest concentration was recorded in June $\left(5047 \mathrm{CFU} / \mathrm{m}^{3}\right)$ in RCEES, and in August $\left(5514 \mathrm{CFU} / \mathrm{m}^{3}\right)$ in $\mathrm{BBG}$. The lowest concentration was found in April in RCEES $\left(286 \mathrm{CFU} / \mathrm{m}^{3}\right)$ and in BBG $\left(380 \mathrm{CFU} / \mathrm{m}^{3}\right)$.

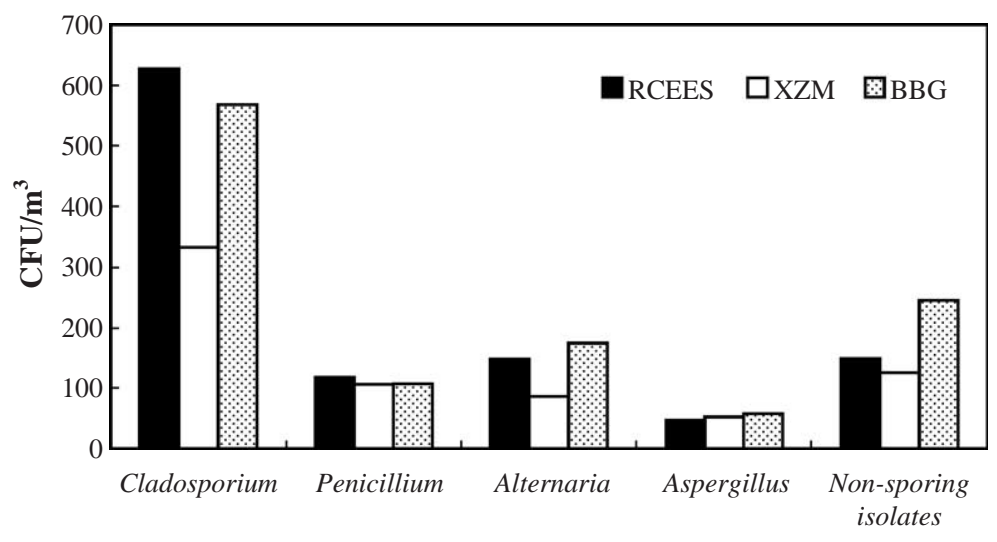

Fig. 1. Dominant fungal concentration in three sampling sites. 
However, the concentrations exhibited no significant differences in XZM throughout the year. In all sampling sites, no significant variations in fungal concentrations were found from November to May $(P>0.05)$ (see Fig. 3).

The same variations were observed between Cladosporium concentrations and total fungal concentrations in three sampling sites during the year. The highest concentration of Cladosporium was recorded in June $\left(2691 \mathrm{CFU} / \mathrm{m}^{3}\right)$ in RCEES, and in August (1936 CFU $\left./ \mathrm{m}^{3}\right)$ in BBG. The lowest concentration was found in April $\left(107 \mathrm{CFU} / \mathrm{m}^{3}\right)$ in RCEES,
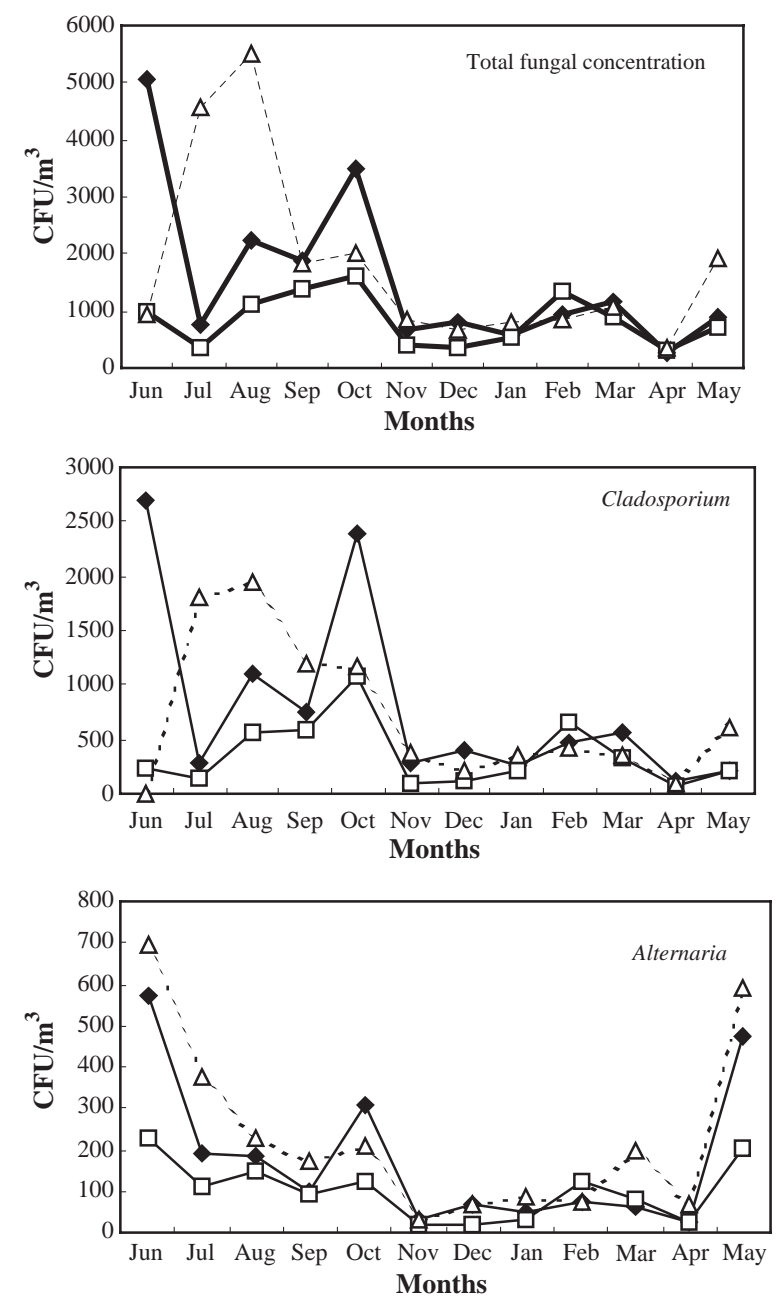

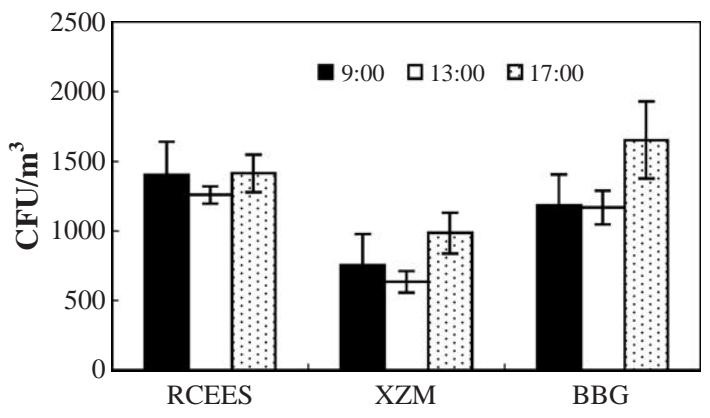

Fig. 4. The diurnal changes of total fungal concentration during three sampling times in a day.
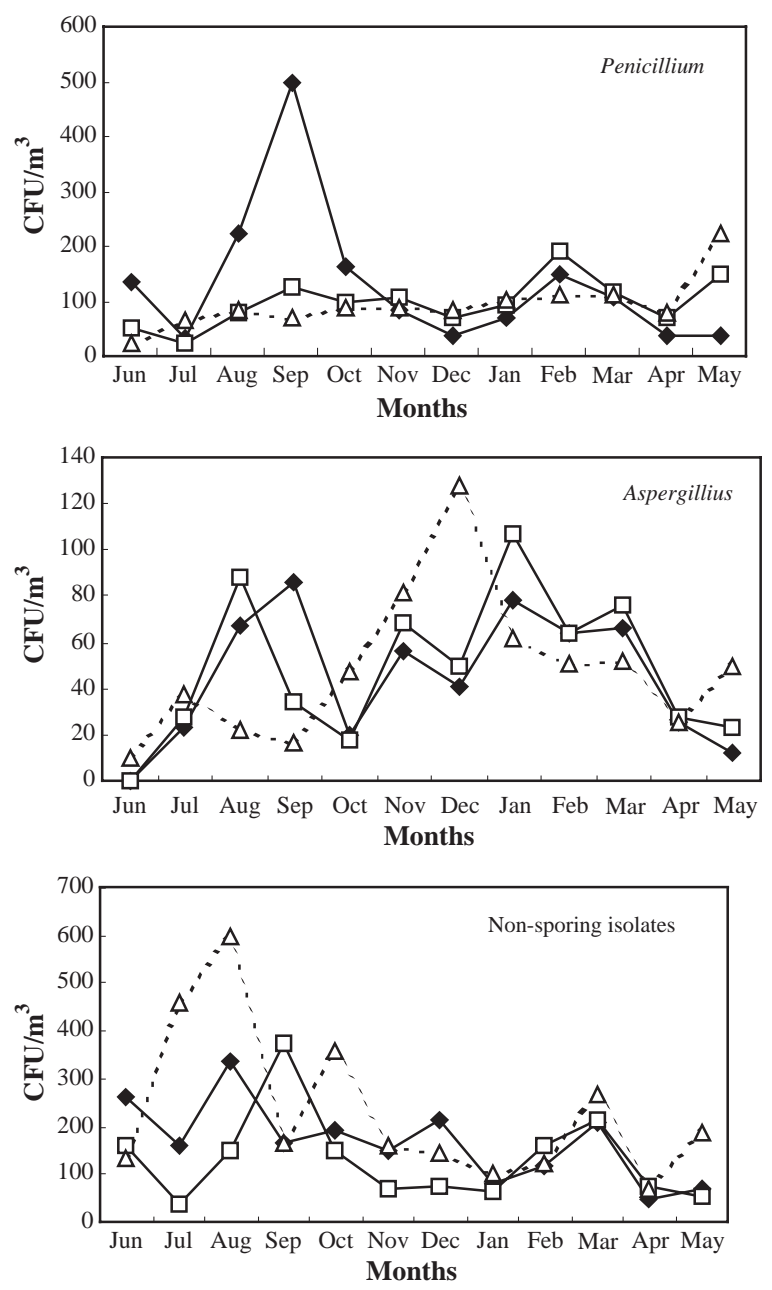

$\longrightarrow$ RCEES $\longrightarrow$ XZM $---\Delta--$ BBR

Fig. 3. Monthly variation pattern of the airborne concentration of culturable fungi in three sampling sites. 



Fig. 5. The diurnal changes of fungal group concentration during three sampling times in a day. 
Table 2

Culturable airborne fungal populations collected by FA-1 sampler

\begin{tabular}{|c|c|c|c|}
\hline Functional areas/genera/species & RCEES & XZM & BBG \\
\hline Actinomucor & & + & \\
\hline A. elegans & & + & \\
\hline Alternaria & + & + & + \\
\hline A. alternata & + & + & + \\
\hline Aspergillus & + & + & + \\
\hline A. clavatus & + & & \\
\hline A. flavus & + & + & + \\
\hline A. niger & + & + & + \\
\hline A. sydowii & & & + \\
\hline Cladosporium & + & + & + \\
\hline C. herbarum & + & + & + \\
\hline C. sphaerospermum & + & & + \\
\hline C. tenuissimum & + & + & + \\
\hline Emerricella & + & & \\
\hline E. nidulans var. nidulans & + & & \\
\hline Endomyces & & & + \\
\hline E. fibuliger & & & + \\
\hline Fusarium & + & + & + \\
\hline $\begin{array}{l}\text { F. chlamydoporum } \\
\text { var. chlamydosporum }\end{array}$ & + & + & + \\
\hline F. verticillioides & + & & + \\
\hline Neosartorya & + & & \\
\hline N. fischeri var. fischeri & + & & \\
\hline Paecilomyces & + & + & + \\
\hline P. varioti & + & + & + \\
\hline Penicillium & + & + & + \\
\hline P. aurantiogriseum & + & & + \\
\hline P. bilaiae & + & & \\
\hline P. brevicompactum & + & + & + \\
\hline P. chrysogenum & + & & \\
\hline P. citreonigrum & & & + \\
\hline P. citrinum & + & + & \\
\hline P. corylophilum & + & & \\
\hline P. crustosum & + & & + \\
\hline P. expansum & + & + & \\
\hline P. funiculosum & + & & \\
\hline P. glabrum & + & + & \\
\hline P. oxalicum & + & & + \\
\hline P. pinophilum & + & + & \\
\hline P. restrictum & & + & \\
\hline \multicolumn{4}{|l|}{ P. roqueforti } \\
\hline P. rubrum & & + & \\
\hline P. steckii & + & + & + \\
\hline P. sydowii & + & & + \\
\hline P. variabile & + & + & + \\
\hline $\begin{array}{l}\text { P. verrucosum } \\
\text { var. verrucosum }\end{array}$ & + & & \\
\hline P. viridicatum & + & & \\
\hline Phoma & + & & \\
\hline P. septicidalis & + & & \\
\hline Talaromyces & + & + & + \\
\hline T. flavus var. flavus & + & + & + \\
\hline Trichoderma & & + & + \\
\hline
\end{tabular}

Table 2 (continued)

\begin{tabular}{llll}
\hline Functional areas/genera/species & RCEES & XZM & BBG \\
\hline T. longibrachiatum & & + & + \\
Trichothecium & + & & + \\
T. roseum & + & & + \\
No-identification & + & + & + \\
\hline
\end{tabular}

and in June in BBG $\left(10 \mathrm{CFU} / \mathrm{m}^{3}\right)$. However, no significant variations of Penicillium concentrations were observed during a year in all sampling sites, except the higher concentration in Sep in RCEES. In all sampling sites, the Alternaria concentrations from May to July were significantly higher than those of other months $\left({ }^{*} P<0.05\right)$, and the variation of Aspergillus concentration was opposite to Alternaria. Concerning non-sporing isolates, the concentration levels in January and April were relatively lower than those in other months (Fig. 3).

\subsubsection{Diurnal changes during three sampling times}

No significant difference of total fungal concentration during three sampling times existed in different sampling sites $(P>0.05)$ (Fig. 4). The highest concentrations of Cladosporium were recorded at 17:00 hours $(* P<0.05)$, and the lowest concentration of Penicillium was found at 13:00 hours in all sampling sites $\left({ }^{*} P<0.05\right)$ (Fig. 5).

\subsection{Fungal groups}

Fourteen genera, including 40 species of culturable fungi, were identified from all sampling sites. The genus of Penicillium with 21 species occupied more than $50 \%$ of the total number of isolated fungal species. The genus of Aspergillus only had four species and genus of Cladosporium had three species. Eleven genera and 31 species were identified in RCEES, and nine genera and 19 species in XZM, 10 genera and 22 species in BBG (see Table 2).

The frequency of the five dominant groups including Cladosporium, non-sporing isolates, Alternaria, Pencillium and Asperigillus, varied from $76.1 \%$ to $98.8 \%$ throughout the year. The frequency of other fungal groups, varied from $0.0 \%$ to $42.6 \%$ (see Table 3).

Within the dominant groups, Cladosporium had the maximum fungal concentration percentage, and 
Table 3

Overall percentage and frequency of airborne fungi in three sampling sites

\begin{tabular}{|c|c|c|c|c|c|c|}
\hline \multirow[t]{2}{*}{ Fungal groups } & \multicolumn{2}{|l|}{ RCEES } & \multicolumn{2}{|l|}{ XZM } & \multicolumn{2}{|l|}{ BBG } \\
\hline & Frequency & $\begin{array}{l}\text { Concentration } \\
\text { percentage }\end{array}$ & Frequency & $\begin{array}{l}\text { Concentration } \\
\text { percentage }\end{array}$ & Frequency & $\begin{array}{l}\text { Concentration } \\
\text { percentage }\end{array}$ \\
\hline Cladosporium & $95.9 \%$ & $43.0 \%$ & $96.4 \%$ & $36.6 \%$ & $98.1 \%$ & $40.7 \%$ \\
\hline Penicillium & $92.3 \%$ & $11.0 \%$ & $95.2 \%$ & $15.5 \%$ & $91.8 \%$ & $11.0 \%$ \\
\hline Alternaria & $95.9 \%$ & $14.0 \%$ & $89.9 \%$ & $11.7 \%$ & $96.9 \%$ & $14.5 \%$ \\
\hline Aspergillus & $81.7 \%$ & $6.5 \%$ & $82.1 \%$ & $8.8 \%$ & $76.1 \%$ & $7.0 \%$ \\
\hline Non-sporing isolates & $98.8 \%$ & $18.0 \%$ & $98.2 \%$ & $18.2 \%$ & $96.9 \%$ & $20.1 \%$ \\
\hline Trichoderma & $7.7 \%$ & $0.1 \%$ & $12.5 \%$ & $0.6 \%$ & $6.9 \%$ & $0.2 \%$ \\
\hline Paecilomyces & $8.9 \%$ & $0.2 \%$ & $11.3 \%$ & $0.7 \%$ & $8.8 \%$ & $0.2 \%$ \\
\hline Mucor & $16.0 \%$ & $0.6 \%$ & $16.7 \%$ & $0.6 \%$ & $21.4 \%$ & $0.6 \%$ \\
\hline Neurospora & $5.9 \%$ & $0.1 \%$ & $4.2 \%$ & $0.1 \%$ & $8.8 \%$ & $0.1 \%$ \\
\hline Yeasts & $42.6 \%$ & $2.2 \%$ & $36.3 \%$ & $2.9 \%$ & $8.2 \%$ & $2.2 \%$ \\
\hline Rhizopus & $3.0 \%$ & $0.0 \%$ & $0.0 \%$ & $0.0 \%$ & $0.0 \%$ & $0.0 \%$ \\
\hline Fusarium & $15.4 \%$ & $0.4 \%$ & $12.5 \%$ & $0.3 \%$ & $11.3 \%$ & $0.3 \%$ \\
\hline No identification & $68.0 \%$ & $3.9 \%$ & $72.6 \%$ & $3.8 \%$ & $75.5 \%$ & $3.2 \%$ \\
\hline
\end{tabular}

accounted for $43.0 \%$ in RCEES, for $36.6 \%$ in XZM, and $40.7 \%$ in BBG, respectively (see Table 3 ). The non-sporing isolates was the second group isolated from the samples, followed by Alternaria, Pencillium and Asperigillus. Their concentration percentages varied from $6.5 \%$ to $20.1 \%$. Other groups accounted for no more than $3.0 \%$ of total fungi colonies.

The concentration percentages of Cladosporium were significantly higher in RCEES than in XZM $\left({ }^{*} P<0.05\right)$. However, the concentration percentages of Penicillium $(* * P<0.01)$ and Aspergillus $(* P<0.05)$ were significantly higher in XZM than in RCEES and in BBG, and no significant differences of concentration percentages in other groups were found in all sampling sites (see Table 3).

\subsection{Particle size distributions of airborne culturable fungi}

The distributions of particle size of total culturable fungi in different sampling sites were showed in Fig. 6. The distributing patterns presented lognormal distribution. The highest proportions of culturable fungi were detected in stage $4(2.0-3.5$ $\mu \mathrm{m})$, and the lowest in stage $6(<1.0 \mu \mathrm{m})$ $(* * P<0.01)$. The proportions were $27.96 \%$ (RCEES), 36.24\% (MTL), and 29.49\% (BBG) in stage 4 , and $5.01 \%$ (RCEES), $4.50 \%$ (XZM), 5.62\% (BBG) in stage 6. On other stages, the proportions varied from $9.96 \%$ to $27.55 \%$ in RCEES, from $9.94 \%$ to $20.66 \%$ in XZM, and from $12.56 \%$ to $20.61 \%$ in BBG.

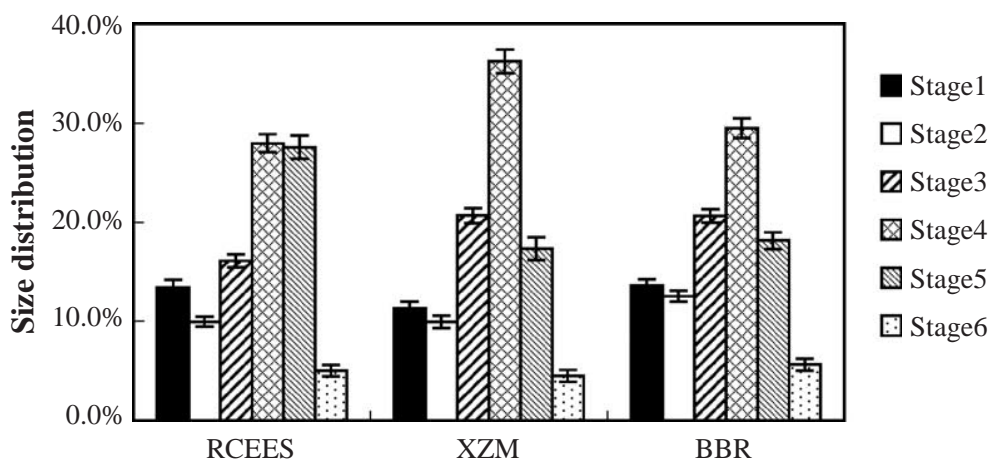

Fig. 6. Relative abundance of total fungi found on the six stages of FA-1 sampler. 
Significant differences of fungal proportions were found at all stages in three sampling sites except stage 6 . The lowest proportions of total culturable fungi were found in stage $1(>8.2 \mu \mathrm{m})\left({ }^{*} P<0.05\right)$, and the highest in stage $4(* * P<0.01)$ in XZM.

\section{Discussion}

In general, the fungal concentration in Beijing was higher compared to the studies conducted in other urban areas (Takahasi, 1997; Rosas et al., 1997; Shelton et al., 2002). It may lead to the serious microbial pollution in the atmosphere in Beijing. The fungal concentrations in the atmosphere varied greatly in different sampling sites during a year in Beijing, and the wide range of those concentrations could be attributed to the micro-environmental and meteorological conditions, sampling time of a day and year, and different climatic conditions in a year (Adhikari et al., 2004). In other studies, there were large differences in total fungal concentrations, and the great variations were also found in the cities of other countries (Giorgio et al., 1996; Rosas et al., 1997; Takahasi, 1997; Al-Suwaine et al., 1999; Zhai et al., 2000; Shelton et al., 2002; Ju et al., 2003). For example, Rosas et al. (1997) reported a geometric mean concentration of $143 \mathrm{CFU} / \mathrm{m}^{3}$ in Mexico city. Shelton et al. (2002) recorded the medium concentration $\left(500 \mathrm{CFU} / \mathrm{m}^{3}\right)$ in the United States. Takahasi (1997) observed a concentration range of 13-2750 $\mathrm{CFU} / \mathrm{m}^{3}$ from the city of Yokohama, Japan. In China, fungal concentrations ranged from $315 \mathrm{CFU} / \mathrm{m}^{3}$ to $4718 \mathrm{CFU} / \mathrm{m}^{3}$ in Lanzhou (Ju et al., 2003); Lv et al. (1996) also observed a fungal concentration ranging from $367 \mathrm{CFU} / \mathrm{m}^{3}$ to $6288 \mathrm{CFU} / \mathrm{m}^{3}$ in Wulumuqi. Those great differences could be attributed to the geographic location, different fungal growth substrates in different countries, as well as different types of sampler, different type of media and different sampling methods used by the researchers (Adhikari et al., 2004).

Significantly high concentration of airborne fungi was observed in the regions with high vegetation coverage in Summer in Beijing. On one hand, most of the fungal airborne spores were supposed to come from vegetation rather than from soil. In the vigorous growth of plants in Summer, the phyllo- planes can allow for the growth of several saprophytic and parasitic fungi (Picco and Rodolfi, 2000). On the other hand, air temperature and moisture in the microenvironment in Summer could be adaptable for the germination, growth and propagation of airborne fungi. This result was consistent with the finding reported by $\mathrm{Ju}$ et al. (2003) who observed that the fungal concentration in the greenbelt was 12 times higher than in the traffic line. In Spring, the urban plants could not flourish because of the climatic conditions in Beijing, and the plants withered away in Winter. There were not enough growth substrates for fungi in the atmosphere around the city, and no significant differences of fungal concentration were found among three sampling sites in Spring and in Winter. Moreover, the human activities might also result in the increase of fungal concentrations in the atmosphere. Therefore, due to about $50 \%$ vegetation coverage and high frequent human activities, such as personnel flow and construction in the campus, a high fungal concentration was also observed in RCEES. In XZM, a low concentration of airborne fungi was recorded. It might be attributed to the lack of vegetation and many other environmental factors inhibiting the growth of fungi in Summer, such as serious pollution, high air temperature and low moisture near the ground.

There was high vegetation coverage in RCEES and in BBG, the leafage could act as the crude substrate of airborne fungi, which would be released into the atmosphere in a certain condition. So the fungal colonization might vary according to the season and the plant life cycle (Picco and Rodolfi, 2000). Therefore, the concentration varied greatly and was higher in Summer and Autumn, and lower in Spring and Winter. Furthermore, the highest fungal concentrations in Summer were also recorded among seasons in RCEES and in BBG because of the suitable conditions for fungal growth such as air temperature and moisture (Rahkonen et al., 1990; Shelton et al., 2002; Kuder, 2003). But there was a much lower vegetation coverage, and a deficiency of fungal sources in XZM. No significant seasonal variation in fungi concentration was recorded during the year. Nevertheless, our result was inconsistent with the study of Huang et al. (2002), who reported that the fungal concentration was higher in Winter 
than other seasons in municipal landfill sites in southern Taiwan and ascribed it to the geographic characteristics of the sampling area.

It was reported that light triggered fungal spores release in several fungi, and light was required to initiate ascopore discharge in many of the bitunicate fungi (Leach, 1975; Lyon et al., 1984; Li and Kendrick, 1994). The study of Salvaggio and Aukrust (1981) showed that conidia of Cladosporium and Alternaria were often abundant during midday periods with maximal sunlight. However, the higher concentrations of Cladosporium were recorded at 17:00 hours $(* P<0.05)$, and the lower concentration of Penicillium was found at 13:00 hours in the present study $\left({ }^{*} P<0.05\right)$. Those results were different from previous studies because the fungal concentrations were determined by many environmental and meteorological factors. There might be other factors influencing the fungal concentrations, although the sunlight was abundant in 13:00 hours.

The prevalent fungal groups from all the sampling sites were Cladosporium, non-sporing isolates, Alternaria, Pencillium and Asperigillus, some of which have been reported as the most common airborne fungi in different environments in other studies (Singh et al., 1995; Pandit et al., 1995; Rosas et al., 1997; Waisel et al., 1997; Picco and Rodolfi, 2000; Shelton et al., 2002; Huang et al., 2002; Hargreaves et al., 2003; Kuder, 2003; Adhikari et al., 2004). Cladosporium, comprising more than one third of the collected samples, was the most dominant fungal group in the present study. The same result was also found by $\mathrm{Wu}$ et al. (1982) and by Fu et al. (2000) in Beijing. However, most of studies in China showed that there were few Cladosporium in the atmosphere (Zhang et al., 1987; Zhai et al., 2000; Ju et al., 2003). It might be caused by the sampling methods (natural sinking method), different sampling environments, and culture medium (potato dextrose agar). The different culture median could permit the isolation of some species of airborne fungi (Morring et al., 1983). Studies showed that some of airborne fungi showed seasonality, corresponding to their seasonal occurrence (Singh et al., 1990). Cladosporium was predominant during Winter months, Alternaria during Summers, while Penicillium species were predominant during Autumn (Singh et al., 1990), but such variation was not found in the present study. However, the concentration variations of different fungal groups were found differently in a year. The variation of Aspergillus concentration was opposite to Alternaria. It might be resulted from the different major sources for different fungal groups. In different environments, despite the similarity of the fungal community composition, there was a great discrepancy of the concentration percentages. It demonstrated that the concentration percentages of fungal groups changed with the environmental and sampling conditions.

The size distributions of airborne fungi in outdoor environments showed that the distributions were similar in different sampling sites, presenting log-normal distribution, which was in accordance with the studies of $\mathrm{Hu}$ et al. (1990) in Beijng and Meklin (2003) in school buildings of two construction types (wooden and concrete). In our study, the highest fungal levels were located in the 2.0-3.5 $\mu \mathrm{m}$ size range, and lowest in $<1.0 \mu \mathrm{m}$, while $\mathrm{Hu}$ et al. (1990) found that the highest fungal levels existed in the size range of 3.0-6.0 $\mu \mathrm{m}$, and in the data of Meklin et al. (2002), the range of 1.1-2.1 $\mu \mathrm{m}$ was the highest across all sampling stages. It suggested that the fungal spores had different sources in different environments (Reponen et al., 1992), and that size distributions were affected by meteorologic factors such as temperature and moisture (Meklin et al., 2002). In the study of Meklin et al. (2002), wooden buildings had mostly traditional organic insulation materials, such as moss or sawdust, which might act as a source of the fungal aerosol. In the present study, the percentage of vegetation coverage was more than $95 \%$ in $\mathrm{BBG}$, where the herbage and shrubbery were the main sources of airborne fungi. In RCEES the fungal spores mainly originated from vegetation or human activities, and in XZM mainly from soil or dust.

\section{Conclusions}

In the present study, an investigation of airborne fungi in outdoor environments was conducted in Beijing, we can conclude that (i) the major contributors to the outdoor environments in Beijing, 
respective, were Cladosporium, non-sporing isolates, Alternaria, Penicilliun and Aspergillus. The genus of most species richness was Penicillium, and the genus of highest concentration was Cladosporium. (ii) there was high fungal concentration in the regions with high vegetation coverage and many human activities, where the concentration of airborne fungi might vary according to the seasonal occurrence and the plant life cycle, and was higher in Summer and Autumn, but lower in Spring and Winter, (iii) in different environments, despite the similarity of fungal community composition, there was a great discrepancy of the concentration percentages, (iv) the size distribution pattern of airborne fungi presented log-normal distribution, the highest proportions of culturable fungi were detected in stage 4 (2.0-3.5 $\mu \mathrm{m})$ and the lowest in stage $6(1.0 \mu \mathrm{m})$.

\section{Acknowledgements}

This study was financially supported by the Project of Knowledge Innovation of the Chinese Academy of Sciences (KZCX3-SW-424). The authors would like to gratefully acknowledge Erich WS from the Center for Ethics in Complex Systems in the U.S.A. who successfully made the technical and grammatical revisions for this paper. The authors would also thank other graduate students and teachers who provided their valuable suggestions in our research group and in the Department of Systems Ecology in the Research Center for Eco-Environmental sciences, Chinese Academy of Sciences.

\section{References}

Adhikari A, Sen MM, Gupta-Bhattacharya S, Chanda S. Airborne viable, non-viable, and allergenic fungi in a rural agricultural area of India: a 2-year study at five outdoor sampling stations. Sci Total Environ 2004;326:123-41.

Al-Suwaine AS, Hasnain SM, Bahkali AH. Viable airborne fungi in Riyadh, Saudi Arabia. Aerobiologia 1999;15:121-30.

Banerjee MC, Weber P, Ruffin J, Banerjee S. Airborne fungi survey of some residences in Durham, North Carolina, USA. Grana 1987;26:103-8.

Bush RK, Portnoy JM. The role and abatement of fungal allergens in allergic diseases. J Allergy Clin Immunol 2001;107:430-40.
Cvetnić Z, Pepeljnjak S. Distribution and mycotoxin-producing ability of some fungal isolates from the air. Atmos Environ 1997;31:491-5.

Fu CL, He WH, Jia JH, Sun ZM, Yuan W, Zhou YG. Special investigation of fungi from four cities of China. Microbiology 2000;27:266-9 (in Chinese).

Giorgio C, Krempff A, Guiraud H, Binder P, Tiret C, Dumenil G. Atmospheric pollution by airborne microorganisms in the city of Marseilles. Atmos Environ 1996;30:155-60.

Halonen M, Stern DA, Wright AL, Taussig LM, Martinez FD. Alternaria as a major allergen for asthma in children raised in a desert environment. Am J Respir Crit Care Med 1997; 155:1356-61.

Hameed AAA, Khodr MI. Suspended particulates and bioaerosols emitted from an agricultural non-point source. J Environ Monit 2001;3:206-9.

Hargreaves M, Parappukkaran S, Morawska L, Hitchins J, He C, Gilbert D. A pilot investigation into association between indoor airborne fungal and non-biological particle concentrations in residential houses in Brisbane, Australia. Sci Total Environ 2003;312:89-101.

Harrison J, Pickering CA, Faragher EB, Austwick PK, Little SA, Lawton L. An investigation of the relationship between microbial and particulate indoor air pollution and the sick building syndrome. Respir Med 1992;86:225-35.

Horner WE, Helbling A, Salvaggio JE, Lehrer SB. Fungal allergens. Clin Microbiol Rev 1995;8:161-79.

Hu QX, Xu GQ, Xu XZ, Shi CY, Chen ZS, Zhang SL, et al. Size distribution of airborne microorganism particle. China Environ Sci 1990;10:99-102 (in Chinese).

Huang CY, Lee CC, Li FC, Ma YP, Su HJJ. The seasonal distribution of bioaerosols in municipal landfill sites: a 3-yr study. Atmos Environ 2002;36:4385-595.

Ju TZ, Suo AN, Tian YJ, Tian YJ, Feng KK. Analysis on aerobiologia in Lanzhou. Ind Saf Environ Prot 2003;29:17-9 (in Chinese).

Kuder EM. Seasonal variations in the occurrence of culturable airborne fungi in outdoor and indoor air in Craców. Int Biodeterior Biodegrad 2003;52:203-5.

Leach CM. Influence of relative humidity and red-infrared radiation on violent spore release by Drechslera turcica and other fungi. Phytopathology 1975;65:1303-12.

Li CS, Hsu LY. Airborne fungal allergen in association with residential characteristics in atopic and control children in a subtropical region. Arch Environ Health 1997;52:72-9.

Li DW, Kendrick B. Functional relations between airborne fungal spores and environmental factors in Kichener-Waterloo, Ontario, as detected by canonical correspondence analysis. Grana 1994;33:166-76.

Li CS, Hsu LY, Chou CC, Hsieh KH. Fungus allergens inside and outside the residences of atopic and control children. Arch Environ Health 1995;50:38-43.

Lv AH, Zou SD, Wang QY, Wang QY, Li SH, Su J, et al. Study on contamination of airborne microbes in Wulumuqi. Arid Environ Monit 1996;10:174-8 (in Chinese).

Lyon FL, Framer CL, Eversmeyer MG. Variations of airspora in the atmosphere due to weather conditions. Grana 1984;23:177-81. 
Meklin T, Reponen T, Toivola M, Koponen V, Husman T, Hyvärinen A, et al. Size distribution of airborne microbes in moisture-damages and reference school building of two construction types. Atmos Environ 2002;36:6031-9.

Morring K, Sorenson W, Attfield M. Sampling for airborne fungi: a statistical comparison of media. Am Ind Hyg Assoc J 1983;44:662-4.

Pandit T, Singh S, Singh AB. Prevalence of culturable and nonculturable airborne fungi in a grain store in Delhi. Aerobiologia 1995;11:177-82.

Picco AM, Rodolfi M. Airborne fungi as biocontaminants at two Milan underground stations. Int Biodeterior Biodegrad 2000;45:43-7.

Rahkonen P, Ettala M, Laukkanen M, Salkinoja-Salonen M. Airborne microbes and endotoxins in the work environment of two sanitary landfills in Finland. Aerosol Sci Tech 1990; 13:505-13.

Ren PT, Jankun TM, Belanger K, Bracken MB, Leaderer BP. The relation between fungal propagules in indoor air and home characteristics. Allergy 2001;56:419-24.

Reponen T, Lehtonen M, Raunemaa R. Effect of indoor sources on fungal spore concentration and size distribution. J Aerosol Sci 1992;23:663-6.

Reponen T, Grishpun S, Reponen A, Ulevicius V. Characteristics of exposure to fungal spores in indoor air. American Industrial Hygiene Association Http://www.aiha.org/abstract/ 6evalbio.html.

Rosas I, Calderón C, Martínez L, Ulloa M, Lacey J. Indoor and outdoor airborne fungal propagule concentrations in Mexico city. Aerobiologia 1997;13:23-30.

Salvaggio J, Aukrust L. Postgraduate course presentations: mould-induced asthma. J Allergy Clin Immumol 1981;68: $327-46$.
Shelton B, Kirkland KH, Flanders WD, Morris GK. Profiles of airborne fungi in buildings and outdoor environments in the United States. Appl Environ Microbiol 2002;68:1743-53.

Singh AB, Chatterji M, Singh BP, Gangal SV. Airborne viable fungi in library: before and after agitation of books. Ind J Aerobiol 1990;3:32-8.

Singh A, Ganguli M, Singh AB. Fungal spores are an important component of library air. Aerobiologia 1995;11:231-7.

Su JH, Rotnitzky A, Burge HA, Spengler JD. Examination of fungi in domestic interiors by using factors analysis: correlations and associations with home factors. Appl Environ Microbiol 1992;58:181-6.

Takahasi T. Airborne fungal colony-forming units in outdoor and indoor environments in Yokohama. Japan Mycopathologia 1997;139:23-33.

Waisel Y, Ganor E, Glikman M, Epstein V, Brenner S. Airborne fungal spores in the coastal plain of Israel: a preliminary survey. Aerobiologia 1997;13:281-7.

Wu CH, Li ZQ, Qi ZT, Xu H. Fluctuation of airborne microfungi over Beijing in a span of 24 years. Huanjing Kexue Xuebao 1982;2:255-61 (in Chinese).

Zhai JH, Cui H, Chen ML, Xu XZ, Sun ZH, Hu QX, et al. Analysis and identification of airborne fungi in Beijing and Nanjing. China Public Health 2000;16 (in Chinese).

Zhang ZL, Wang ZF, Wang PL. An ecological investigation of the airborne fungus and bacteria in an urban environment 1 . Category distribution of the airborne microorganisms. China Environ Sci 1987;7:43-7 (in Chinese). 